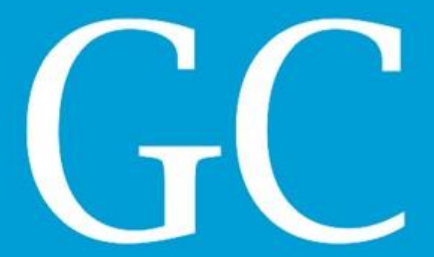

Revista Nacional de

Gerenciamento de Cidades
ISSN 2318-8472

v. 06, n. 43,2018

\title{
Gestão Urbana: Parque Linear Sétimo Céu, Passo Fundo, RS
}

Urban Management: Linear Park Seventh Heaven, Passo Fundo, RS

Gestión Urbana: Parque Lineal Séptimo Cielo, Paso Fundo, RS

Mirian Carasek

Professora Mestre, UPF, Brasil

miriancarasek@upf.br

\section{Evanisa Fátima Reginato Quevedo Melo}

Professora Doutora, UPF, Brasil evanisa@upf.br

\section{Ricardo Henryque Reginato Quevedo Melo}

Professor Mestre, IMED, Brasil ricardo.melo@imed.edu.br 


\section{INTRODUÇÃO}

A questão histórica dos parques urbanos tem modificado seus usos em função do rápido crescimento das cidades. O parque vem despertando o interesse como uma ferramenta para o planejamento podendo ser um corredor verde, um eixo estruturador de programas ambientais e atuando como um espaço multifuncional (Mora, 2013; Mota, 2013; Brasil, 2016: Giaretta,2016).

Parques lineares urbanos são áreas verdes que melhoram a qualidade de vida da população ao proporcionar contato com a natureza. Seguindo essa tendência foi entregue à população em junho de 2017, o Parque Linear do Sétimo Céu transformou em área de lazer um espaço que antes era pouco ocupado pela população, mas que é um dos cenários mais bonitos de Passo Fundo. As intervenções continuam e o local passou por um incremento de paisagismo, onde a Prefeitura de Passo Fundo investiu em novas espécies vegetais, entre elas arbustos e flores, além do aumento dos espaços gramados (PASSO FUNDO, 2015). Um Parque Linear é constituído por espaços lineares, quadras centrais de uma avenida; tendo como principal característica a capacidade de interligar fragmentos de vegetação e outros elementos encontrados em uma paisagem. Neste tipo de parque têm-se a agregação de funções de uso humano, expressas principalmente por atividades de lazer, cultura e rotas de locomoção não motorizada, como ciclovias e caminhos de pedestres. São obras estruturadoras de programas ambientais em áreas urbanas, sendo muito utilizados como instrumento de planejamento e gestão de áreas degradadas, buscando conciliar tanto os aspectos urbanos e ambientais como as exigências da legislação e a realidade existente; podendo ajudam a evitar a ocupação humana irregular em áreas de proteção ambiental.

Figura 1: Localização de espaços verdes e de praças de Passo Fundo, RS.

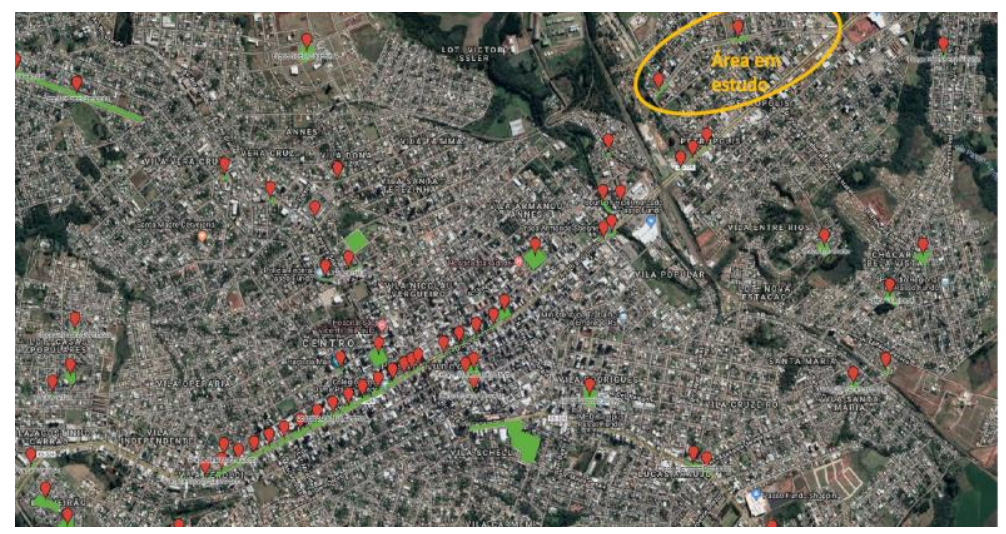

Fonte: PASSO FUNDO, 2018 (b) 
O mapa das praças de Passo Fundo (Figura1), identifica todos os pontos registrados na prefeitura como praças, parques, canteiros e terreiros; no modelo de praça desenvolvido baseado não apenas na valorização dos aspectos estéticos, mas também nos aspectos simbólicos e funcionais. Esses projetos de reestruturação urbana visavam à constituição de um cenário marcante, destacado pelos edifícios e pelas funções que desempenhavam no conjunto urbano. Essas praças cumpriam o papel de marco urbano, de ponto de referência na estrutura da paisagem e, em função dessas características, ainda permanecem como espaços simbólicos na atualidade (TEIXEIRA, 2001, p. 77).

A Figura 2 mostra a localização da avenida com largos canteiros, sobre os quais se localiza o Parque Linear, uma área urbana, em bairro próximo do centro da cidade. A Avenida Rui Barbosa tem início na avenida Brasil, - principal via de acesso ao centro de Passo Fundo; segue por aproximadamente 1500 metros de extensão e área, sendo de $12 \mathrm{~m} 2$, em onze canteiros, até o denominado Sétimo Céu; - ponto elevado, que permite a visualização de diversos bairros da cidade, incluindo o centro.

O parque atende diretamente a uma população aproximada de 20 mil pessoas, tendo sido projetado a fim de permitir vários tipos de atividades e interesses (Figura 2); que propiciem melhora da saúde, como ciclovia, pista de caminhada ou a academia ao ar livre; e espaços recreacionais, bem com alguns ambientes de permanência, espaço com mesas de xadrez, situadas próximas à área da academia ao ar livre, área esportiva com quadra poliesportiva, cancha de bocha e pista de skate. 


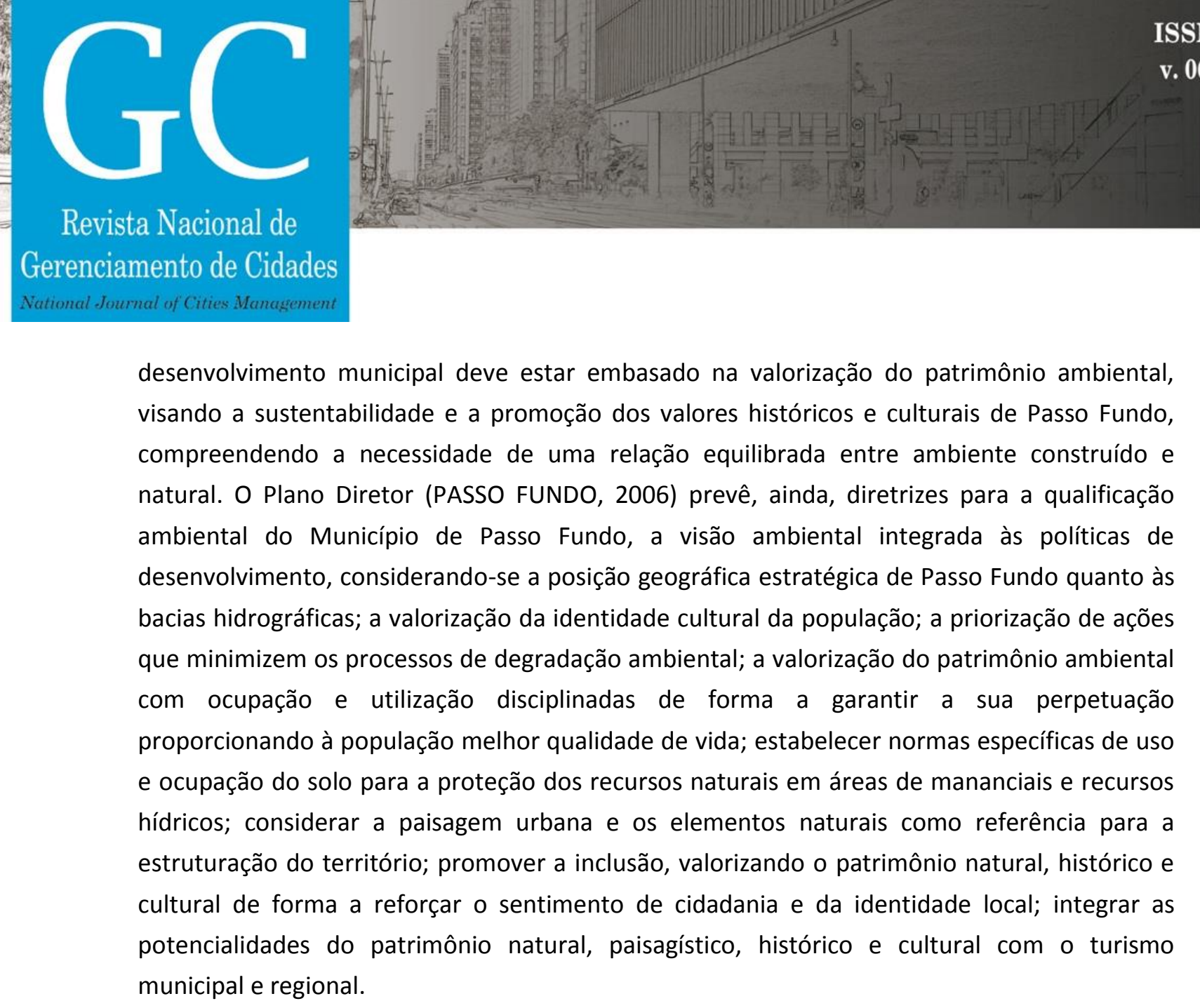

\section{PASSO FUNDO: PARQUE LINEAR SÉTIMO CÉU}

O trecho do parque tem aproximadamente, $1500 \mathrm{~m}$ e, se caracteriza por uma conformação geométrica heterogênea, com grandes diferenças no perfil recortado e com marcação importante quando existem edifícios altos. As tipologias arquitetônicas apresentam soluções próprias, com linguagens diferenciadas, que somente fazem referência à atividade e à possibilidade de exaltar sua presença no entorno. A arborização dos passeios é variada e mal distribuída, sendo que, na maioria das quadras analisadas, não existe vegetação alguma; apenas a vegetação existente nas delimitações do parque. 


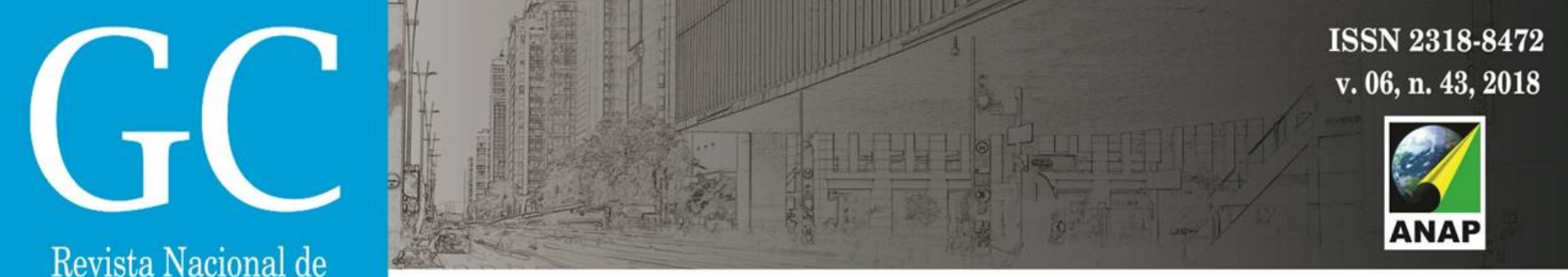

Gerenciamento de Cidades

A análise do ambiente construído pode ser realizada a partir de diversos enfoques; sendo o morfológico um deles. Nele, são esboçadas as diferentes leituras da cidade e dos componentes da manifestação dos significados do entrono urbano, leitura geométrica. A Figura 4 mostra a volumetria das edificações ao longo do Parque Linear, suas localizações na parte da malha urbana em estudo e a numeração das quadras analisadas na abordagem e análise dos aspectos geométricos e vivenciais nas tipologias, a seguir.

Tabela 1: Analise da quadra 1

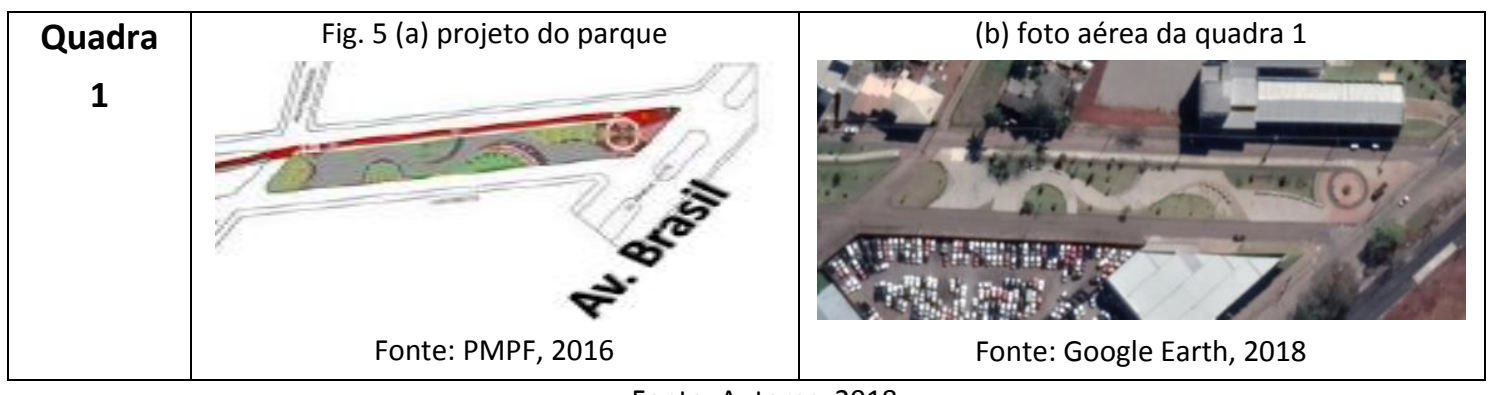

Fonte: Autoras, 2018

Equipamento e mobiliário urbano

- Parada de ônibus da av. Brasil

- Playground

- Academia ao ar livre

- Mesas com tabuleiro

- Espaços de estar e contemplação

- Canteiros

- Ciclovia

- Pista de caminhada

\section{Diagnóstico}

Quadra longa com aproximadamente 190 metros de comprimento vistos na tabela 1; figuras 5 (a) e (b). Onde se localizam grande parte dos equipamentos e mobiliários urbanos disponíveis no parque. Esta quadra está localizada em frente à uma faculdade, sendo a mais próxima da avenida Brasil, a principal via arterial da cidade. Esta quadra é uma das mais movimentadas do parque. Seja por sua proximidade com a avenida Brasil, - via de acesso à cidade e de grande fluxo; seja pela concentração de equipamentos e mobiliário urbanos. A parada de ônibus recebe coletivos urbanos e ônibus de transporte de estudantes, vindos de outras cidades próximas. A pavimentação foi feita com piso intertravado, com canteiros, com pouca vegetação; algumas delas inseridas na implantação do parque. A região tem baixo índice de 


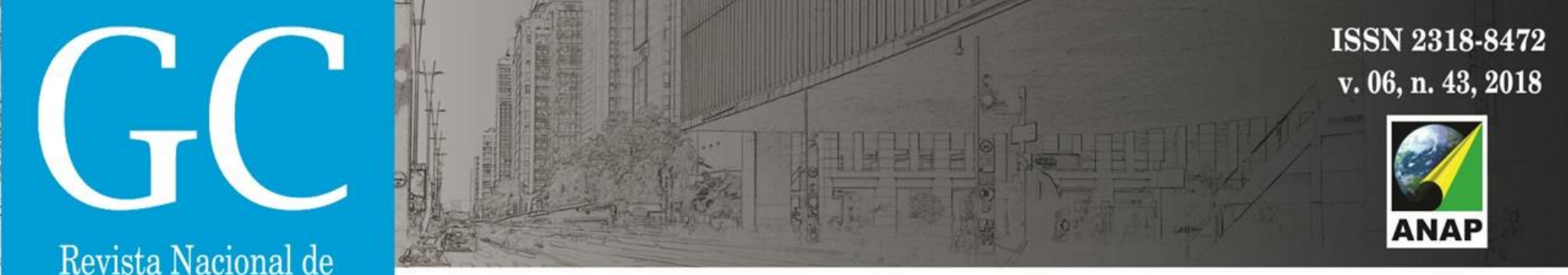

Gerenciamento de Cidades

vegetação nativa. Ao longo do parque, esta é uma das quadras mais tratadas, com canteiros de flores, espaços de estar e contemplação, mesas com tabuleiro e academia ao ar livre, que propiciam oportunidade aos visitantes de maior permanência. Aqui, também se encontram algumas das poucas lixeiras do parque. No que tange à acessibilidade; esta quadra apresenta desníveis com a via esquerda da avenida Rui Barbosa, que não permitem o acesso de pessoas com deficiência à praça. No entanto, próximo à parada de ônibus, há rampas para cadeirantes e piso podo-tátil.

A ciclovia e a pista de caminhada partem dessa quadra e seguem ao longo do traçado do parque. Segundo o Caderno de Referência para a Elaboração de Plano de Mobilidade por Bicicletas nas Cidades, publicado pelo Ministério das Cidades (BRASIL, 2007), os seguintes fatores são as principais influências na mobilidade dos ciclistas: largura e adequação da pista, segurança e continuidade da infraestrutura, sinalização, iluminação, equipamentos de apoio ao usuário (bebedouros e banheiros, por exemplo), estacionamentos seguros e bem distribuídos, e integração com outros modos de transporte. Assim, fica estabelecido que um plano de apoio e incentivo ao ciclismo necessita mais do que um sistema viário bem dimensionado.

Tabela 2: Analise da quadra 5

\begin{tabular}{|c|c|c|}
\hline $\begin{array}{c}\text { Quadra } \\
5\end{array}$ & Fig. 6 (a) projeto do parque & (b) foto aérea da quadra 5 \\
\hline & Fonte: PMPF, 2016 & Fonte: Google Earth, 2018 \\
\hline
\end{tabular}

Fonte: Autores, 2018

Equipamento e mobiliário urbano

- Cancha de bocha

- Quadra poliesportiva

- Espaços de estar e contemplação

- Bicicletário para bicicletas compartilhadas

- Ciclovia

- Pista de caminhada

Diagnóstico

Originalmente, antes da formação do parque, já existia uma quadra poliesportiva aqui. O projeto e execução deste espaço de lazer, com 150 metros de extensão, recuperou a quadra de esportes, acrescentando uma cancha de bocha, espaços de estar com 


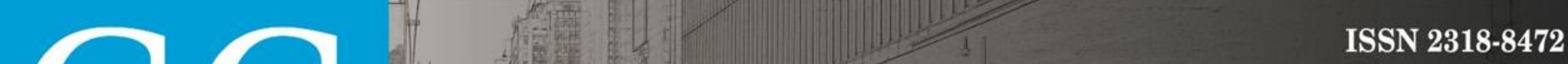

Revista Nacional de

bancos, na Tabela 2, Figuras 6 (a) e (b). Também há lixeiras, canteiros, piso podo-tátil; este, instalado de forma errônea. Não só não leva a lugar algum, como pode conduzir a pessoa com restrição visual, para dentro da pista de caminhada e ciclovia, onde pode sofrer um acidente. Ali, também foi instalado um bicicletário; infelizmente pouco usado; ainda à espera da mudança de hábitos.

Tabela 3: Analise da quadra 10

\begin{tabular}{|c|c|c|}
\hline $\begin{array}{l}\text { Quadra } \\
10\end{array}$ & Fig. 7 (a) projeto do parque & (b) foto aérea da quadra 10 \\
& \\
& Fonte: PMPF, 2016 & Fonte: Google Earth, 2018 \\
\hline
\end{tabular}

Fonte: Autoras, 2018

Equipamento e mobiliário urbano

- Pista de skate

- Espaços de estar e contemplação

- Ciclovia

- Pista de caminhada

Diagnóstico: Esta quadra, como na Tabela 3, Figuras 7 (a) e (b) tem 20 m de extensão; forma a terceira praça dentro do parque; criando ambientes de convivência e de permanência. Aqui o ponto de foco é a pista de skate; bem utilizada pelos aficionados pelo esporte. Conta, também, com ambiente de estar, lixeiras e canteiros plantados. 


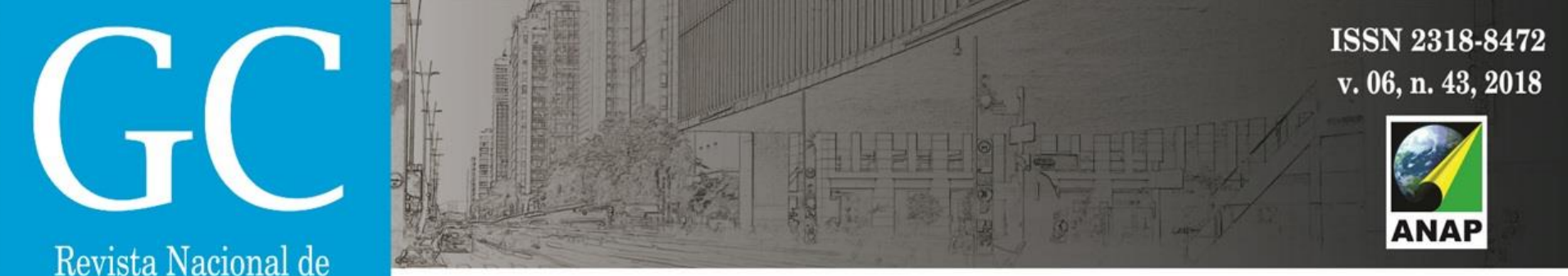

Tabela 4: Analise das quadras 2,3,4, 6,7,8,9

\begin{tabular}{|c|c|c|}
\hline $\begin{array}{c}\text { Quadra } \\
2\end{array}$ & Fig. 8 (a) projeto do parque & $\begin{array}{l}\text { (b) foto aérea da quadra } 2 \\
\text { Fonte: Google Earth, } 2018\end{array}$ \\
\hline $\begin{array}{c}\text { Quadra } \\
3\end{array}$ & (c) projeto do parque & $\begin{array}{l}\text { (d) foto aérea da quadra } 3 \\
\text { Fonte: Google Earth, } 2018\end{array}$ \\
\hline $\begin{array}{c}\text { Quadra } \\
4\end{array}$ & (e) projeto do parque & (f) foto aérea da quadra 4 \\
\hline $\begin{array}{c}\text { Quadra } \\
6\end{array}$ & $\begin{array}{l}\text { Fig } 9 \text { (a) projeto do parque } \\
150 \text { metros de extensão } \\
\text { Fonte: PMPF, } 2016\end{array}$ & (b) foto aérea da quadra 6 \\
\hline $\begin{array}{c}\text { Quadra } \\
7\end{array}$ & $\begin{array}{l}\text { (c) projeto do parque } \\
\text { Quaris rurts rmm } 70 \mathrm{~m} \\
\text { Fonte: PMPF, } 2016\end{array}$ & $\begin{array}{l}\text { (d) foto aérea da quadra } 7 \\
\text { Fonte: Google Earth, } 2018\end{array}$ \\
\hline $\begin{array}{c}\text { Quadra } \\
8\end{array}$ & $\begin{array}{l}\text { (e) projeto do parque } \\
\text { Espaço intermerliárin entre rótulas, } 50 \mathrm{~m}\end{array}$ & (f) foto aérea da quadra 8 \\
\hline $\begin{array}{c}\text { Quadra } \\
9\end{array}$ & $\begin{array}{l}\text { (g) projeto do parque } \\
\text { Tem } 260 \text { metros de extensão } \\
\text { Fonte: pMrr, } 2010\end{array}$ & $\begin{array}{l}\text { (h) foto aérea da quadra } 9 \\
\text { Fonte: Google Earth, } 2018\end{array}$ \\
\hline
\end{tabular}

Fonte: Autoras, 2018

Equipamento e mobiliário urbano existente nas quadras 2,3 e 4

- Ciclovia 


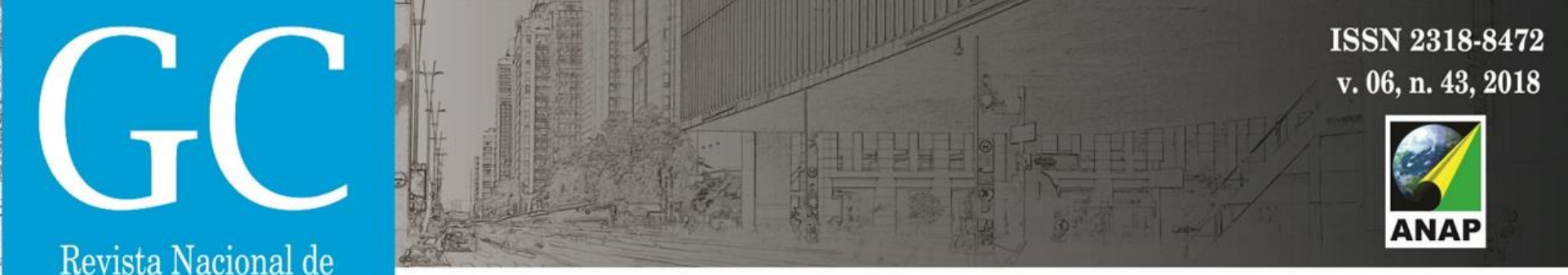

Revista Nacional de Gerenciamento de Cidades

- Pista de caminhada

- Quadra 4 - Área de estacionamento

Equipamento e mobiliário urbano existente nas quadras 6,7,8 e 9

- Ciclovia

- Pista de caminhada

Diagnóstico:

A presença da ciclovia e da pista de caminhada integraram os diversos ambientes do parque, como se pode observar em Figura 8 (a), (b), (c), (d), (e) e (f) e, figura 9 (a), (b), (c), (d), (e), (f), (g) e (h). Porém, seguem as carências de estruturas de apoio, como recomendado pelo Ministério das Cidades (BRASIL, 2007). Não há lixeiras ou espaços de descanso e contemplação ao longo desses mais de $1000 \mathrm{~m}$, em prejuízo ao lazer e ao meio ambiente. A sinalização é discreta com acento na sinalização de controle de transito de veículos.

Faltam espaços sombreados pois o parque, como todo tem pouca vegetação arbustiva ou de grande porte. Na quadra 4, foi incorporado, ainda, um recuo de estacionamento obliquo. Essas quadras também apresentam pouco, ou nenhum equipamento de acessibilidade. Sendo que, os meio fios tem altura variadas, em prejuízo a pessoas com baixa mobilidade; o bairro tem alto índice de pessoas com idade acima de 60 anos.

\section{RECOMENDAÇÕES}

O parque, tal como é, traz benefícios arrolados. Porém, pode haver melhorias, tais como arroladas por Zilliacus (2018): Incentiva as mais diversas topografias a servirem como pontos de encontro, mas também para gerir a água da chuva, com utilização de artes vibrantes, mobiliários diferenciados e vegetação são implementos que podem ajudar a atrair pessoas para os parques, bem como enfatizar visualmente a sua presença. Esta estratégia pode ter um resultado interessante e de baixo custo. No parque em estudo, o implemento da arte, mobiliários e vegetação adequada ao longo das quadras, também se faz possível. Incluir espaços de convivência, são boas estratégias para convidar às atividades mais comuns e atraentes para a população.

Esta estratégia pode ser a de maior alcance entre as propostas, especialmente por grande parte dela já estar indicada nos diagnósticos do parque e seu entorno. Ruas são utilizadas por todas as pessoas, todos os dias. Elas são "o tecido que conecta a cidade", mas como elas podem ser transformadas em lugares? Através do desenvolvimento de uma cobertura dinâmica para os pedestres estarem protegidos, melhorando a 'caminhabilidade' das ruas e a saúde pública de uma comunidade. Além disso, o desenvolvimento de lojas e o apoio de eventos locais irá fornecer uma forma de entretenimento para os pedestres, bem como 
incentivar os gastos locais estimulando o crescimento econômico. Plantar árvores pode resolver o aumento de calor urbano e projetar a superfície das ruas pode otimizar a gestão das águas pluviais, além de aumentar as opções de mobilidade.

\section{CONCLUSÕES}

Os resultados apresentados neste artigo são resultados parciais de uma análise mais ampla sobre o parque e seu entorno. A implantação do parque como tal, demonstra grande sensibilidade da municipalidade em relação ao lazer da comunidade e a abertura de um caminho, ainda incipiente que conduza ao respeito ao meio ambiente. Especialmente, quando se percebe a proximidade com áreas de preservação ambiental. A análise das mudanças ocorridas na tipologia construtiva existente ao longo da avenida demonstra aumento no gabarito das edificações, com consequente adensamento populacional. Deste modo, parques públicos se mostram como importante estratégia para uma política efetiva do projeto urbano. Percebe-se que o Parque Linear Sétimo Céu apresenta diferentes relacionamentos com as proximidades em sua busca com a natureza e o meio urbano - comunidades diferentes, apropriações contrastantes que vem demonstrando sua importância na consolidação do município de Passo Fundo, RS, integrando a área construída com responsabilidade na preservação da paisagem, mostrando adensamento populacional no bairro devido a fatores decorrentes da implantação do parque linear.

A partir das observações realizadas e das recomendações feitas, pode-se perceber os resultados ocorridos e imaginar outros mais, sobre os efeitos benéficos do parque no bairro, numa reflexão sobre a cidade que queremos e precisamos.

O parque linear Sétimo Céu revitalizou o espaço público e fortaleceu o papel da cidade como um fórum democrático, assim como promoveu melhoria estética e paisagística, criando a perspectiva de crescimento do verde na cidade, bem como apresenta potencial para gerar conectividade e valorização no bairro e na cidade em diferentes níveis, minimizando a fragmentação espacial preservado promovendo identidade do lugar.

\section{REFERENCIAS BIBLIOGRAFICAS}

BRASIL. Cidades, Rio Grande do Sul, Passo Fundo. Disponível em: <https://cidades.ibge.gov.br/brasil/rs/passofundo/panorama>. Acesso em: 20.ago.2018

BRASIL. Ministério do Meio Ambiente. Parques e Áreas Verdes. Disponível em:<http://www.mma.gov.br/cidadessustentaveis/areas-verdes-urbanas/parques-e-áreas-verdes>. Acesso em 07 jul. 2016 


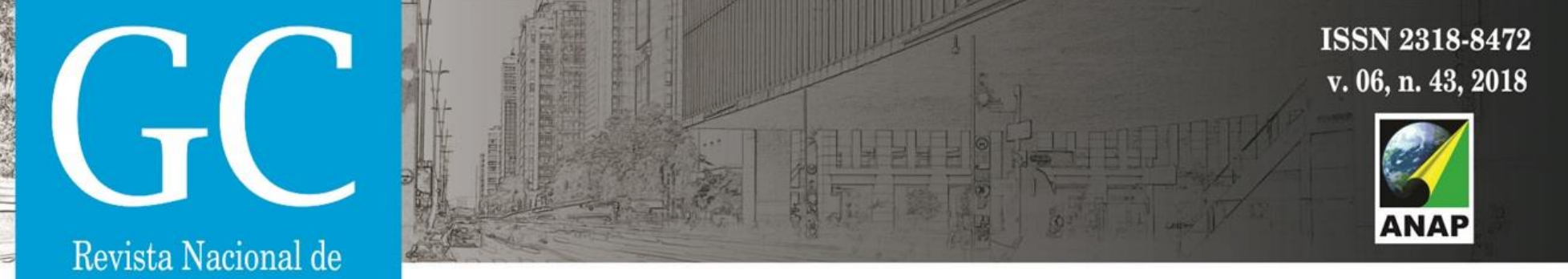

Gerenciamento de Cidades

National Joumal of Cities Management

DE ANGELIS, Bruno Luiz Domingos; CASTRO, Rosana Miranda de; ANGELIS NETO, Generoso De. Metodologia para levantamento, cadastramento, diagnóstico e avaliação de praças no Brasil. Revista de Engenharia Civil. Universidade do Minho. Braga, n. 20, p. 57-70, 2004.

GIARETTA, F. Meio ambiente, espaço urbano e políticas de imagem: o caso do Parque Linear Ribeirão das Pedras (Barão Geraldo, Campinas, SP). Boletim campineiro de geografia, v. 6, n.2, p. 479-500, 2016

MORA, N. M. Experiências de parques lineares no Brasil: espaços multifuncionais com o potencial de oferecer alternativas a problemas de drenagem e águas urbanas. Banco Interamericano de Desarrollo 2013 83p. (Nota técnica do BID ; 518)

MOTA, E. Projeto Técnico: Parques Lineares como medidas de manejo de águas pluviais. ABCP: Associação Brasileira de Cimento Portland. Programa Soluções para Cidades. Disponível em <http://www.solucoesparacidades.com.br/wp-content/uploads/2013/10/AF_Parques\%20 Lineares_Web.pdf> Acesso em ago.2018

PASSO FUNDO. PMPF. Autorizada obra do Parque Linear do Sétimo Céu. Disponível em $<$ http://www.pmpf.rs.gov.br/interna.php?t=19\&c=11\&i=10198> Acesso em 16.outubro. 2018

PMPF. Mapas de Praças em Passo Fundo. Disponível em <https://www.google.com/maps/d/u/0/embed?mid=127coYbTU5BHjHr5pgtt_ywv7DXs\&Il=28.25678341163437\%2 C-52.40069444466985\&z=15>. Acesso em 19.outubro.2018

Lei complementar no 170, de 09 de outubro de 2006. Dispõe sobre o Plano Diretor de Desenvolvimento Integrado - PDDI do Município de Passo Fundo. Disponível em: <http://www.pmpf.rs.gov.br/files/lei-comp-170pddi.pdf>. Acesso em: out. 2018.

RIO GRANDE DO SUL. SEMC. Secretaria de Energia, Minas e Comunicações. Atlas Eólico do Rio Grande do Sul. 2002

TEIXEIRA, Manuel (Coord.). A praça na cidade Portuguesa: colóquio Portugal Brasil. Lisboa: Livros Horizontes, 2001.

ZILLIACUS, A. "Studio Gang cria 7 estratégias para requalificar espaços cívicos" [Studio Gang Creates 7 Strategies to Reimagine Civic Spaces As Vibrant Urban Hubs] 25 Out 2016. ArchDaily Brasil. (Trad. Sbeghen Ghisleni, Camila) ISSN 0719-8906. Disponível em: <https://www.archdaily.com.br/br/797949/studio-gang-cria-7-estrategias-pararequalificar-espacos-civicos> Acesso em 24 ago. 2018 